Research article

\title{
Challenges faced by novice Emirati teachers
}

\author{
Martina Dickson*, Julie Riddlebarger, Patricia Stringer, Lilly Tennant, Keith \\ Kennetz \\ *martina_dickson@hotmail.com
}

DOI: http://dx.doi.org/10.5339/nmejre.2014.4

Submitted: 8 January 2014

Accepted: 9 May 2014

Running head: Dickson et al. NMEJRE 2014:4

Cite this article as: Dickson M, Riddlebarger J, Stringer P, Tennant L, Kennetz K. Challenges faced by novice Emirati teachers, Near and Middle Eastern Journal of Research in Education 2014:4 http://dx.doi.org/10.5339/nmejre.2014.4

Copyright: 2014 Dickson M, Riddlebarger J, Stringer P, Tennant L, Kennetz K, licensee Bloomsbury Qatar Foundation Journals. This is an open access article distributed under the terms of the Creative Commons Attribution license CC BY-4.0, which permits unrestricted use, distribution and reproduction in any medium, provided the original work is properly cited.

THIS PROVISIONAL PDF CORRESPONDS TO THE AUTHOR-SUPPLIED ARTICLE AS IT WAS ACCEPTED. FULLY FORMATTED PDF AND HTML VERSIONS WILL BE MADE AVAILABLE SOON.

This peer-reviewed article, like all on QScience.com, was published immediately upon acceptance. It can be downloaded, printed and distributed freely provided the original work is properly attributed.

For information about publishing your research in QScience.com journals, please go to http://authorsqscience.com/ 


\title{
Challenges faced by Emirati novice teachers
}

\author{
Martina Dickson ${ }^{1, *}$, Julie Riddlebarger ${ }^{2}$, Patricia Stringer ${ }^{3}$, Lilly Tennant \\ ${ }^{3}$, Keith Kennetz ${ }^{3}$
}

1. *Emirates College for Advanced Education, Abu Dhabi, UAE, PO BOX 11361 martina_dickson@hotmail.com, mdickson@ecae.ac.ae

2. Khalifa University, Abu Dhabi, UAE

3. Emirates College for Advanced Education, Abu Dhabi, UAE

\section{Abstract}

The first years of teaching are well known as being the most challenging of new graduates' careers, corresponding to the highest attrition rates. Numbers of novice teachers leaving the profession during the first three years are universally high. The challenges faced by novice teachers vary from struggling with classroom management issues to coping with lesson planning, to name just two. In Abu Dhabi, the capital city of the United Arab Emirates, novice Emirati teachers face additional dimensions to these challenges, in that they are joining public schools which are undergoing substantial educational reform. They are also in the minority as Emirati English medium teachers, working among mainly Western teaching staff. We interviewed a group of Emirati primary school teachers during their first year of teaching. It was found that they had faced multiple challenges, some of which are universal among novice teachers, such as managing student behavior and learning to cope with their new workload. However, they also faced additional unique challenges, such as navigating inter-cultural relationships with colleagues, and balancing their new working lives with their demanding home lives.

Keywords: Novice Teachers, Emirati, government schools, challenges, United Arab Emirates 


\section{Background}

\section{Teaching in government schools in the UAE}

Government schools in the United Arab Emirates (UAE) have been involved in significant educational reform over the past six or seven years. This was instigated by a series of reports and public declarations about the inadequacies of the educational system, which was then described as antiquated and inadequate by some (Abu Dhabi Education Council, 2008). In answer to these growing criticisms, ADEC rolled out the New School Model in 2010. This was a series of curriculum standards for the subjects of mathematics, science and English, which were to be taught through the medium of English. Native English speaking teachers were hired from overseas to work in primary schools, predominantly from the U.S.A, Canada, U.K. and Australia (El Ajou, 2009). These are known as English Medium Teachers (EMTs), while the teachers of the Arabic medium subjects such as social studies, Islamic education and Arabic language are known as Arabic Medium Teachers (AMTs).

At the same time, the UAE authorities had an important on-going agenda of Emiratisation, which prioritized the employment of Emirati citizens where possible (Mashood, Verhoeven, \& Chansarkar, 2009) in both public and private sectors. There arose an urgent need for Emirati teachers who were able to fulfill the demands of Abu Dhabi Educational Council's (ADEC) New School Model, i.e. teach using modern approaches to learning such as student-centered learning. Additionally, they should be able to deliver the English medium subjects with nativelevel proficiency in the English language. Education programs in teacher-training institutions in Abu Dhabi were either adapted, or set up specifically, to create this type of graduate. The novelty of this situation brings up all kinds of new challenges and situations. Even experienced Emirati teachers are known to have struggled to cope in this environment of fast track reforms, and expressed dissatisfaction and considered leaving the profession (Troudi \& Alwan, 2010;

Gallagher, 2011; Badri, Mohaidat, Ferrandino \& El Mourad, 2013).

\section{Novice teachers - 'immigrants in a new country'}

The novice teacher's experience has been described in various ways, such as that they are 'immigrants in a new country' (Sabar, 2004), their experience is comparable to a 'revolving door' (Ingersoll, 2001), which "cannibalizes its young" and in which the initiation of new teachers is akin to a "sink or swim boot-camp" (Smith and Ingersoll, 2004, p.682). According to Martin (2008), the introduction of novice teachers creates a strain, not only for the novice teachers themselves, but for the whole 
school, including already overstretched principals. It is widely accepted in contemporary literature that some of the common challenges to novice teachers include classroom management struggles, unsupportive working environments, inadequate preparation time and lack of administrative support (McCoy, 2003; Kelsey, 2006; Melnick \& Meister, 2008; Elliott, Stemler, Sternberg, Grigorenko \& Hoffman, 2011, Goodwin, 2012).

Teacher attrition in the early years is a universal problem. Guarino, Santibañez, and Daley (2006) state that "one very stable finding is that attrition is high for young teachers" (p. 185), a finding which corroborated an earlier study by Hanushek, Kain, and Rivkin (2004). Novice teachers' initial focus in the early years is often on basic survival, being so overwhelmed by the tasks which teaching entails (Katz, 1972; Huberman, 1989; Feiman-Nemser \& Remillard, 1996). The importance of a mentoring scheme for novice teachers, and the detrimental consequences of lack of such a scheme, has been documented by researchers both internationally (e.g. Ponticell \& Zepeda, 1996; Sabar, 2004; Beck and Kosnick, 2007; McCormack \& Gore, 2008; Ingersoll \& Strong, 2011) and in the UAE (Ibrahim, 2012). Furthermore, Clark and Byrnes (2012) found that novice teachers who received planning time with a mentor and release time to observe other teachers, rated the mentoring experiences they had as significantly more helpful than those who had not received this support.

In addition to the day-to-day struggles novice teachers may encounter, they are often especially challenged by conflicts between their personal beliefs and the reality of teaching, and can begin to lose some of their earlier confidence under the scrutiny of observations (Bullough, 1997; Brown, 2006; Fitzgerald, Dawson \& Hackling, 2008). Long, Hall, Conway and Murphy (2012) found that the novice teachers in their study preferred to remain invisible as learners, preferring "never to confront their own learning needs as teachers" (p. 621) and being unsure of how to negotiate their professional identity. This is concerning, not least because the process of learning and practicing as teachers enables them to become effective teachers and without this feedback, growth is less likely to occur.

For novice teachers, being away from the 'safe' and familiar environment of their teacher training college can be very isolating and may add to the pressure they experience during their early years. Feeling part of a community and experiencing positive collegiality within this has been found to be an important part of a teacher's continuing professional education (Hashim \& Ahmad, 2013). They describe how, in order for teachers to develop expertise in their field, they need support from colleagues. Indeed, quality of professional 
relationships with school colleagues can greatly impact novice teachers' development (McNally, Cope, Inglis \& Stronach, 1997, in Elliott et al, 2011). All of this points to a critical time in a teacher's career, which needs careful examination in order to provide the correct support and attempt to allay high attrition rates in the early years. This is now discussed within the context of teacher attrition with the context of the UAE.

\section{Emirati teacher attrition in Abu Dhabi}

Al Kaabi (2005) prefaced his doctoral thesis with the statement that "In 2005, attrition among teachers is a significant problem in the United Arab Emirates, a problem that limits the ambition of the country to develop its educational system." (p. 1). More recent data on Emirati teacher attrition shows that the problem has shown no sign of abating, and in fact since the onset of the educational reform in 2009-2010, has increased (Table 1).

Table 1: Attrition statistics of Emirati teachers in Abu Dhabi

\begin{tabular}{|l|c|c|}
\hline $\begin{array}{l}\text { Academic } \\
\text { Year }\end{array}$ & $\begin{array}{l}\text { Number of Emirati teachers } \\
\text { in government schools in } \\
\text { Abu Dhabi Emirate* }\end{array}$ & $\begin{array}{l}\text { Attrition of UAE citizen } \\
\text { teachers between } \\
\text { successive academic years }\end{array}$ \\
\hline $2007 / 2008$ & 3651 & +349 \\
\hline $2008 / 2009$ & 4000 & -802 \\
\hline $2009 / 2010$ & 3198 & -90 \\
\hline $2010 / 2011$ & 3108 & -155 \\
\hline $2011 / 2012$ & 2953 & \\
\hline
\end{tabular}

*Sources: Statistical Yearbook of Abu Dhabi 2009, 2010, 2011, 2013 and 2013.

These statistics comprise of teaching staff, which includes school administrative staff such as vice-principals and principals, so the attrition cannot be attributed to promotion of classroom teachers to these positions. Some factors associated with the high attrition rate among Emirati public school teachers were earlier found to be new career prospects, difficulties faced in teaching, personal factors, economic and employment factors, and social-cultural factors (Al Kaabi, 2005). Little or no research exists on the reasons for the high attrition rates (as seen in Table 1) since 2009/2010, but since the New School Model was rolled out during this academic year, there is a high possibility that this was one of the factors contributing to these rates. Whether or not they consist of novice or experienced teachers, is also unknown. However, it can be inferred from the literature referred to in the earlier section that novice teachers are at a high risk of attrition. 
Both the Ministry of Education of the UAE and ADEC emphasize increasing the number of Emirati teachers, stating as critical goals in their long-term strategic plans that they should be "role modelsinstilling in students the values of education, of Emirati society, and of good citizenship, and creating responsible and socially aware individuals with strong work ethics" (UAE Ministry of Education, 2010, p. 24). The Ministry of Education also held a goal of having $90 \%$ of teachers in government schools being Emirati citizens by 2020, which seems ambitious given that the percentage of Emirati teachers in Abu Dhabi is currently $43 \%$. Various initiatives to recruit and retain Emirati teachers have been rolled out, including a recently announced $25-30 \%$ pay increase for teachers in Abu Dhabi in attempt to allay attrition (Pennington, 2013). How effective this measure will be in curbing teacher attrition remains to be seen. Guarino et al (2006) comment in their review of empirical literature of teacher recruitment and retention that most attrition is voluntary and that "individuals whose opportunity costs outweigh the rewards gained from teaching will be more likely to leave the teaching professions" (p. 175). This is a particularly significant statement within the context of the UAE, with much higher salaries offered in areas of the public employment sector other than teaching. Exploring Emirati teachers' challenges is important, since without knowledge of these it is difficult to attempt to curb attrition.

\section{Conceptual framework}

The conceptual framework was based upon an ecological perspective, which informed the research questions and development of the data collection tool. Consideration was given to the potential challenges faced by a novice teacher at the micro, meso and macro levels, based on the evidence available in the literature. At the micro level, issues based around workload of planning and preparation of lessons, learning to work with new colleagues and day-to-day classroom issues such as dealing with students' parents, were anticipated. Challenges at the meso level, it was hypothesized, might be created by school policy, lack of a formal mentoring system, and possibly certain gaps in their teacher preparation. Finally, it was thought that there would be scope for challenges at a macro level resulting from the emirate-wide educational reform policies spearheaded by ADEC.

\section{Methodology}

\section{Research question}

A single wide and over-arching research question was used to guide the entire study: What were the main challenges faced by the novice Emirati teachers during their first year of teaching? 


\section{Participants}

A non-probability, purposive sampling approach was utilized in the study. The participants were all graduates of a Bachelor in Education program, and the first graduating cohort from a newly established educational teacher-training college. This study took place towards the end of their first year of teaching. The average age of the participants was 23. The sample was made up of six graduates who were teaching at primary school. They consisted of five females and one male teacher, all teaching a grade between 1 and 5 in a government school in Abu Dhabi. They were all citizens of the United Arab Emirates and referred to as Emirati.

\section{Data collection and analysis}

Qualitative data was collected through participant interviews lasting around thirty minutes each. The research question guided the construction of the interview questions. Specific in-depth questions were asked about participants' experiences in schools so far, in particular focusing on the areas which they were finding challenging. Information about their rights as participants was given both verbally and in writing, and written consent was obtained both for their participation and for the audio recording of the interviews. These recordings were later transcribed. The general approach to coding data described by Miles and Huberman (1994) was adopted. Firstly, a list of codes connected to the interview questions are developed prior to data collection. Codes were then kept, adapted or discarded for their fit (or lack of) to the data. Similarly, as the analysis cycle processed and multiple interviews were analysed, more codes were added as they emerged from data. Codes were attached to phrases and sentences of the transcripts, and codes with similar labels were grouped as themes, a process which underwent a rigorous process of blind inter-coder reliability checking.

\section{Results and discussion}

Six major areas of challenges faced by the novice teachers emerged from the interview data, which will be addressed individually:

- Classroom management

- Implementing the curriculum to mixed ability classes (through the medium of English) and a perceived lack of resources to do this

- Administrative demands and a perception of a lack of support to deal with these

- Relationships with colleagues

- Dealing with parents of students

- Balancing home and family life 


\section{Challenge: Classroom management}

Most of the novice teachers talked of struggling at times to deal with their students' behavior. This is a finding in common with many other researchers, e.g. (Keltchermans \& Ballet, 2002). One of the teachers said that she felt she had no option but to let a student sit directly beside her for the day, watching them to make sure that they would not misbehave. Although most described classroom management as a challenge, there was a clear sense of the novice teachers' developing identity and confidence as they experimented with various classroom management strategies in a trial and error approach. One spoke of her struggle to keep her classroom management consistent, such as when she was trying to teach over students shouting out 'miss, miss' and losing focus on what she was trying to teach. This is a natural part of the progression from novice to experienced teacher and suggests a level of reflection necessary for those changes to be made.

Research has consistently shown that a teacher's competency in classroom management is critical, and consequently not achieving competency in this area may result in novice teachers leaving the profession (Brophy, 1988; Johns, McNaughton \& Karabinus, 1989). A recent study by Ünal and Ünal (2012) concluded, "as teachers become more experienced, they become more controlling on both behavior and instructional management" (p. 50). When one of the teachers was asked what they found most challenging about managing behaviors in their class, they responded that:

The high level students are also so noisy but they do their work so I could not punish them as they are doing very well.

This suggests, perhaps, that the novice teacher would like to be in more control than she feels, and indicates some discomfort with students being 'noisy' whilst at work, which might be perceived as a healthy buzz by a more experienced teacher. One said that she had to go to the school social worker for helping in dealing with challenging behavior, again suggesting a lack of confidence to implement their own management strategies autonomously. One teacher spoke of the challenge of classroom management as being shocking to her, as she found herself teaching violent students who physically hurt one another, which she had not expected. One participant articulates the conflict of the novice teacher, struggling to establish her identity as an authoritative teacher, oscillating between being kind and caring, and firm:

It's really hard if you appear to the students that you can't manage your class, you are not in control ... if they see me 
as weak in the first three weeks or month, and think they are able to talk when I talk, they won't listen to me anymore [sic].

They have yet to find their balance, and it seems in the meantime, are tending towards an increasingly more authoritarian role, which may be a move away from their earlier classroom management ideals. This resonates with Brown (2006), who states that novice teachers can be conflicted by personal, possibly optimistic beliefs, and the reality of teaching.

\section{Challenge: Implementing the curriculum (through the medium of English) and a perceived lack of resources to do this}

Goodwin (2012) wrote of the 'curricular freedom' which many modern, student-centered curriculum models are based upon, purportedly to provide teachers with more flexibility and creativity in the classroom, but perceived by some as providing no "guidance and resources for lesson and unit planning" (p. 84). The novice teachers in the current study described the challenges of getting to grips with the new and unfamiliar curriculum, coupled with the administrative demands of being a teacher. Prior to the educational reforms of 2009/2010, ADEC's predecessor, the Ministry of Education, allowed no deviation from the highly prescriptive lesson plans and textbooks they provided. Perhaps because they feel the need for greater guidance, some teachers described their frustrations at having to create resources which are no longer ready-developed for schools. As a consequence perhaps, a lack of resources was mentioned frequently as a perceived challenge.

The New School Model requires the delivery of the mathematics, science and English curriculum through the medium of English, which created frustrations for some. These novice teachers of course have a unique advantage of being bilingual, in theory. However, the use of Arabic for EMTs to ease delivery of concepts appeared to be controversial, with some teachers reporting that their principals had specifically forbidden them to use Arabic in the classroom. This was a challenge for some due to the variety in their students' language levels, and they felt that using some occasional Arabic to explain underlying concepts was acceptable:

The first two weeks I used English and nobody listened, then I used Arabic and in two days everyone tried to follow the rules and instructions. So English isn't suitable in the classroom all the time. 
One teacher described the conflict she felt at speaking in English to young students, since it was obvious from her appearance (the wearing of national dress) that she was in fact Emirati, and the children asked her why they were speaking in English. One teacher pretended not to be able to understand Arabic in an attempt to counteract those requests.

The teachers also described their struggle to cope with teaching the curriculum in a way which would enable their mixed ability students to access learning, feeling that lower-level students were a particular challenge to deal with. One of the teachers made a reference to there being three levels of ability, low, medium, high, a semi-traditionalist model of differentiation still used frequently in schools. Perhaps teacher preparation has a role to play here in explaining the somewhat artificial nature of this modeling, although in more recent years a variety of differentiation strategies has been brought into pedagogy courses in an attempt to overcome these issues. One teacher compared the levels of students she had dealt with previously during school practicum (mixed) with her present students, whom she described as being overall much lower.

The New School Model has been rolled out on a year-by-year basis, adding on an additional year this year to include grade 5 . Some of the teachers felt that this resulted in them feeling unprepared to teach that particular grade, and this lack of familiarity was compounded by the fact that resources, materials and curriculum for this grade were not readily available for use during their college preparation. This was perceived as a challenge at times.

\section{Challenge: Administrative demands on the novice teacher and perceived lack of support}

Teaching can be an isolating job, particularly for primary school teachers with one class where large amounts of time are spent in their classroom with little peer interaction or feedback (McCormack \& Gore, 2008). Other novice teachers, too, whilst perhaps not the best people to provide teaching advice, can play an important role in the form of peer support by simply listening, validating, and sharing the experience. This is not possible (other than via some form of alumni organization) if the novice teacher is placed alone in a school, which happens very often for a variety of reasons. One reason being the perceived strain of dealing with several new and inexperienced faculty on a school and school principal (Martin, 2008).

There was a perception that support was lacking for the myriad of tasks which a novice teacher faces, such as coming to grips with 
responsibilities, including administrative tasks, which can be overwhelming for a new teacher. One specifically wished they had someone to help guide them with certain administration tasks, such as the student grading system which they considered a major challenge:

Nobody sat with us and told us how to do it, and what will happen ... if you made some mistakes here. No, no, no, no. Just ..."try and go and do it and then, if there is any problem, come and talk to us" [sic]

Depending on a novice teacher to independently 'come and talk' to administrators in a culture where saving face is of extreme importance, may not be appropriate, especially so for less confident individuals. Novice teachers are also more likely to fear appearing to be a 'nuisance' by asking questions. One said that she did have support from her Head of Faculty, but was uncertain over how much help to ask for, whether it was her right to ask or whether she was overstepping some boundary with requests for help. She specifically mentioned that she would like to have a person to go to ask 'silly' questions, and worried that she did not even know if it was this person's job to offer support. Another teacher echoed this:

Sometimes I am afraid of asking my Head of Faculty, you know because, we are twenty-two English teachers, and she is one...

The accountability and necessary paperwork which teaching involves, such as evidence gathering, student and teacher portfolio preparation, etc., was raised as a challenge. Again, this is an area in which perhaps increased support with administrative tasks may have helped the novice teachers to feel less overwhelmed. One teacher went so far as to say that:

The amount of paper work that I have to do was shocking and to most of the teachers teaching was like a "subheading" and less important ... it still shocks me that for each single thing I do I have to have an evidence for it. [sic]

This teacher perceived others to be prioritizing paperwork and evidence above teaching itself, which is at odds with her idealistic views. In addition, as bilingual Emirati teachers within the school community, some participants spoke of feeling pressurized to act as translators, which they found difficult to refuse, and voiced concern that they were being examined as newcomers to see how far they 
could be pushed.

\section{Challenge: Relationships with colleagues}

Relationships with colleagues have been repeatedly found to influence novice teachers' feelings of job satisfaction and sense of success with students, and ultimately their job retention chances (Fantilli \& McDougall, 2009; Okumus \& Biber, 2011). As discussed in the introduction to this article, these novice teachers are in a unique position due to their role as Emirati EMTs among mainly Western EMTs. Generally, it was felt that having teachers of different nationalities and cultures in the same school was testing at times. One teacher described how, although she worked alongside her Western colleagues, she was acutely aware of not being 'one of them' and always sat with the Arab staff at lunchtimes, those being the ones whom she identified and felt most comfortable with. Understandably, amidst the uncertainty of most aspects of her new teaching life, this teacher clings to the familiarity which women from her own culture can provide at these times:

During the break-time the Arabic teachers always invite me to have food and sit with them. You prefer to sit with the person who shares your language, your customs and traditions, but that doesn't mean that I want to eliminate them [the Western EMTs]... it's just ... natural.

Sometimes there was a positive side to the inter-cultural situation, and the novice teachers were able to view both 'sides' from their unique viewpoint of being a bilingual, EMT Emirati teacher. One teacher highlighted what he considered to be misunderstandings between the groups of teachers, and suggested that both groups would benefit from learning one another's language, even going so far as to suggest teaching the EMTs Arabic himself. This may be a very interesting twist in future in schools as more Emirati EMTs graduate are recruited, and are able to fill this language and cultural gap between the groups of teachers.

Kaunitz, Spokane, Lissitz and Strein (1986) spoke of pre-service teachers having some "unique concerns, such as being liked and accepted by students, classroom cooperative teachers and staff " ( $p$ 213). Apparently this is also a concern for the novice teachers in this study, and many mentioned the importance of peer support and simply being able to chat about the same students. There is much evidence in the literature that gaining support from colleagues, feeling socially comfortable and having both personal and professional support from colleagues is critical in the first years of a teacher's journey, as well as 
for teacher retention. However, some teachers felt that their colleagues were not as helpful as they might be, as one learned when she dropped into other teachers' classes and saw that they were using resources which they had not shared with her. The experience resulted in the novice teacher feeling "surprised, shocked, and alone". Another felt the same, but wondered if this was partly as a result of their lack of social interaction:

Sometimes you feel that they [the other EMTs] prefer to work by themselves...not with me... even like the worksheets they are not exchanging or sharing with me [sic]. I don't know if this is just me. I don't know what the problem is. Maybe because I'm not sitting with them a lot.

When asked about their relationship with other Emirati (Arabic Medium) teachers, their responses ranged from feeling a part of that community much more so than with the EMTs, such as:

The Emirati teachers are so happy to have me, they are proud... They told me it's like they are honoured to have Emirati teachers who can teach maths, science and English, and they wished more teachers are coming like me, they are welcoming me a lot in a personal way...

to feeling that "they [the Emirati teachers] consider me as a western EMT anyways!"

For some of these graduates, the only Westerners they have come into close contact with have been the college faculty during their courses, which is an entirely different power dynamic relationship than the one they need to forge daily on an equal footing with their EMT colleagues, as is clear from this comment:

At the beginning of the year I felt they were not happy with me. I don't know why... it's just I don't understand their facial expressions, I don't know what's going on...some of them are tough...with me, cold... so I'm trying to be good with them and show them that you are welcome in our country.

It is clear that these inter-cultural relationships, and their related lack of understanding, caused challenges for the novice teachers at times.

\section{Challenge: Dealing with parents of students}

This subject arose as a perceived challenge to the novice teachers in 
various ways. One teacher talked of the challenge of dealing with parents when there was a mismatch between the parents' idea of their child and the reality of their child's ability in the classroom. Some felt that this was an area in which the college preparation could have been stronger, by providing strategies for dealing with confrontation and dealing with sensitive situations. One teacher described meeting parents who were demanding to know why their child had not performed as they had hoped, and feeling confident in being able to defend the child's grade because of the evidence she had collected. This is an example of the way in which the novice teachers are dealing with challenges, aided by an emerging sense of confidence. The following statement may also exemplify this:

Sometimes the parents want my number but I don't give it to them - I want to keep my privacy, and I didn't want to talk to them on the weekends or my holiday so I let the social worker do the work, and the parents can come any time during the day.

This indicates that the novice teacher is beginning to carve out boundaries and limits for their own sake, which she may not have felt able to do at the beginning of the year. Some talked of the apathy which they felt some parents exhibited in terms of communication and attendance at meetings, only seeing a small number of the parents, numerous times, and finding this a challenge to deal with.

These findings echo those by other researchers. For example, participants in a study by Rieg, Paquette and Chen (2007) thought that "dealing with parents was difficult during their initial teaching experience" citing that parents called or wrote every day, which was stressful to deal with, or that they were "frequently questioned by parents as to how the children were behaviorally and academically assessed" (p. 220).

\section{Challenge: Balancing work and home life demands}

In the previously mentioned study by Rieg, Paquette and Chen (2007), novice teachers named 'striking a balance between school and personal commitments' as one of the three most stressful areas. Just over half of teachers in that study found workload and time management to be a stressor all or most of the time. Similarly, the novice teachers in this study shared these concerns and found trying to achieve a balance between their work and home responsibilities a major challenge.

Emirati culture is very family-oriented and women have many 
responsibilities in the home, particularly for those who are married with families (Bristol-Rhys, 2010). The female teachers talked of the expectation to visit various relatives in the evenings and at weekends when they needed to be preparing lessons or marking student work. One teacher used the very effective metaphor of trying to catch a train to explain how she felt:

At this moment I feel that I don't have balance, and sometimes I feel that I'm not able to accomplish what's required from me, like for example marking, correcting the students'note-books, or checking their books ... sometimes I just catch the beginning of this train but sometimes I feel that I'm lost [sic].

The challenge of the time management factor came up repeatedly, in common with numerous research studies of novice teachers (e.g. Corrie, 2000; Griffin et al, 2008; Fry, 2009). Only one of the interviewed teachers felt that the work-life balance was possible to achieve, and explained her coping strategy:

I don't go home until I finish all my work at work. So when I go home, I have nothing to do at home, it's already done at school. And I have my own time. [sic]

Most of the novice EMTs who participated in this study were allocated a lighter teaching schedule than their more experienced counterparts. Some voiced concern about how they would manage the proposed 'normal' teaching schedule in the subsequent year:

Maybe for the next year they will give me 30 periods which is really horrible... How am I going to teach this? I see that all EMTs are struggling with this, they are so tired!

It could well be that this perception of their forthcoming year may contribute to higher attrition rates.

\section{Conclusion}

Researchers He and Cooper (2011) reflected on whether "participation in research itself served as a venue for teachers to reflect on their practice and discuss their concerns as first year teachers" (p. 112). It was also our experience whilst carrying out this research that the reflection involved in answering our interview questions seemed valuable to the novice teachers. Teacher education programs should encourage such communities among graduates and support their 
sharing and reflection in their first year (also He and Cooper, 2011). At the time of writing, there was no such system in place for these novice teachers. Some of the challenges described in this paper are found universally in most literature searches around novice teachers' experiences, for example managing the classroom (which most novice teachers struggle with initially), managing workload, classroom management, administrative demands and a perception of a lack of support to deal with this, dealing with a new curriculum and a perceived lack of resources to do this. However, some of the challenges our participants faced are unique to their position as Emirati English medium teachers, working in the vast minority alongside Western EMTs. It is hoped that the results of this study will be useful for local educational systems in helping them to understand the concerns of these teachers better, in order to offer better levels of support and consequently healthier retention rates.

The novice teachers in this study described a challenging first year working in government schools in Abu Dhabi. The more aware that school senior management staff and teacher recruiters at the educational council level are of these challenges, the more likely it is that they may be able to make adaptations to make the novice teachers' journey a smoother one. Dealing with the novice teachers' challenges is critical to retention. This is particularly so, given high attrition rates of Emirati teachers, along with the current political agenda in the UAE of prioritizing Emiratisation. Evidence from this study also suggests that teacher-training institutions should take care to better prepare students for teaching by aligning training more closely to the realities of teaching.

\section{Acknowledgments}

The authors would like to whole-heartedly acknowledge and thank the novice teachers who took part in this research and gave so much thought and time to their answers.

\section{References}

Abu Dhabi Education Council. (2008). Together, ADEC Newsletter, 1, 1. Abu Dhabi: Abu Dhabi Education Council. Al Kaabi, A. S. (2005). Factors Influencing Teachers Attrition in the United Arab Emirates. Doctoral dissertation presented to the University of Pittsburgh.

Badri, M., Mohaidat, J., Ferrandino, V.\& El Mourad, T. (2013). The social cognitive model of job satisfaction among teachers: Testing and validation. International Journal of Educational Research, 57, 12-24. 
Beck, C. \& Kosnick, C. (2007). Preparation for the first year of teaching: Beginning teachers' views about their needs. The New Educator, 3(1), 51-73.

Bristol-Rhys, J. (2010). Emirati women: Generations of change. New York: Columbia University Press.

Brophy, J. (1988). Educating teachers about managing classrooms and students. Teaching and Teacher Education. 4(1), 1-18.

Brown, T. (2006). Negotiating psychological disturbance in pre-service teacher education. Teaching and Teacher Education, 22, 675-689.

Bullough, R. V. (1997). Practicing theory and theorizing practice. In J. Loughran, \& T. Russell (Eds.), Purpose, passion and pedagogy in teacher education (13-31). London: Falmer Press.

Clark, S.K. \& Byrnes, D. Through the eyes of the novice teacher: perceptions of mentoring support. Teacher Development, 16(1), 43-54.

Corrie, L. (2000). Facilitating newly qualified teachers' growth as collaborative practitioners. Asia-Pacific Journal of Teacher Education, 28(2), 112-121.

El Ajou, N. (2009). ADEC welcomes new teachers. AMEinfo.com. Retrieved November 2013 from http://www.ameinfo.com/207362.html

Elliott, J.G., Stemler, S.E., Sternberg, R.J., Grigorenko, E.L. and Hoffman, N. (2011). The socially skilled teacher and the development of tacit knowledge. British Educational Research Journal. 37(1), 83-103.

Fantilli, R.D. \& McDougall, D.E. (2009). A study of novice teachers: Challenges and supports in the first years. Teaching and Teacher Education, 25(6), 825-841.

Feiman-Nemser, S., \& Remillard, J. (1996). Perspectives on learning to teach. In F. B. Murray (Ed.), The teacher educator's handbook (pp. 6391). San Francisco: Jossey-Bass Publishers. Fitzgerald, A., Dawson, V. \& Hackling, M. (2008). Perceptions and pedagogy: Exploring the beliefs and practices of an effective primary science teacher. Teaching Science, 55(2). Fry, S.W. (2009). Characteristics and experiences that contribute to novice elementary teachers' success and efficacy. Teacher Education Quarterly, 36(2), 95-110.

Gallagher, K. (2011). Becoming and re-becoming a teacher in the Arabian Peninsula: Amal's story of hope. Teacher Development, 15(2), 141-155.

Goodwin, B. (2012). Research says new teachers face three common challenges. Supporting Beginning Teachers, 69(8), 84-85. 
Griffin, C.C., Kilgore, K.L., Winn, T.A., \& Otis-Wilborn, A. (2008). First year special educators' relationships with their general education colleagues. Teacher Education Quarterly, Winter 2008, 141-157.

Guarino, C. M., Santibañez, L., \& Daley, G. A. (2006). Teacher recruitment and retention: A review of the recent empirical literature. Review of Educational Research, 76(2), 173-208.

Hanushek, E., Kain, J., \& Rivkin, S. (2004). Why public schools lose teachers. Journal of Human Resources, 39(2), 326-354.

Hashim, H. \& Ahmad, S. (2013). Perspectives: Professional journey of the expert teacher educator. Human Resource Development International, 16(4), 471-479.

He, Y. \& Cooper, J. (2011). Struggles and strategies in teaching: Voices of five novice secondary teachers. Teacher Education Quarterly, 38(2), 97-116.

Huberman, M. (1989). The professional life cycle of teachers. Teachers College Record, 91(1), 31-56.

Ibrahim, A. (2012). Induction and Mentoring of novice teachers: a scheme for the United Arab Emirates. Teacher Development, 16(2), 235-253.

Ingersoll, R.M. (2001). Teacher turnover, teacher shortages, and the organization of schools. Seattle, Washington: University of Washington Centre for Study of Teaching and Policy Report.

Johns, F.A., McNaughton, R.H. \& Karabinus, N.G. (1989). School discipline guidebook: Theory into practice. Boston: Allyn and Bacon.

Kaunitz, N., Spokane, A.R., Lissitz, R.W. \& Strein, W.O. (1986). Stress in student teachers: A multidimensional scaling analysis of elicited stressful situations. Teaching and Teacher Education, 2(2), 169-180.

Kelsey, K.D. (2006). Teacher Attrition among women in secondary agricultural education. Journal of Agricultural Education. 47(3), 117129.

Keltchermans, G., \& Ballet, K. (2002). The micro-politics of teacher induction: A narrative-biographical study on teacher socialisation. Teaching and Teacher Education, 18, 105-120.

Long, F., Hall, K., Conway P., \& Murphy, R. (2012). Novice teachers as 'invisible' learners, Teachers and Teaching: theory and practice, 18(6), 619-636.

Martin, P. (2008). Novice Teachers: Meeting the Challenge. Principal. 
November/December, 42-44.

Mashood, N., Verhoeven, H., \& Chansarkar, B. (2009). Emiratisation, Omanisation and Saudisation-common causes: common solutions? 10th International Business Research Conference, Dubai, UAE, 16th17th April.

McCormack, A. \& Gore, J. (2008). "If only I could just teach": Early career teachers, their colleagues, and operations of power. Paper presented December 2008 at the Annual Conference of the Australian Association for Research in Education. Queensland University of Technology, Brisbane, Australia.

McCoy, L.P. (2003). It's a hard job: A study of novice teachers' perspectives on why teachers leave the profession. Current Issues in Education, 6(7). http://cie.ed.asu.edu/volume6/number7/

McNally, J., Cope, P., Inglis, B. \& Stronach, I. (1997) The student teacher in school: conditions for development, Teaching and Teacher Education, 13(5), 485-498.

Melnick, S. \& Meister, D. (2008). A comparison of beginning and experienced teachers' concerns. Educational Research Quarterly, 31(3), 39-56.

Miles, M. B., \& Huberman, A. M. (1994). Qualitative data analysis: An expanded sourcebook (2nd ed.). Newbury Park, CA: Sage.

Okumus, S. \& Biber, B. (2011). A review of novice teachers' relationships among their colleagues, peers and administrators studies: Aims, methodologies, general knowledge claims and suggestions. Western Anatolia Journal of Educational Science Special Issue, pp. 921.

Pennington, R. (2013). Female teachers at Abu Dhabi public schools get pay rise. The National, November 26, 2013. Retrieved December 2013 from: http://www.thenational.ae/uae/education/female-teachersat-abu-dhabi-public-schools-get-pay-rise

Ponticell, J.A., \& Zepeda, S.J. (1996). Making sense of teaching and learning: a case study of mentor and beginning teacher problem solving. In D.J. Mclntyre \& D.M. Byrd (Eds.), Research on field experiences: Teacher education yearbook IV (pp. 115-130). Thousand Oaks, CA: Corwin Press.

Rieg, S.A., Paquette, K.R., \& Chen, Y. (2007). Coping with stress: An investigation of novice teachers' stressors in the elementary classroom. Education, 128 (2), 211-217. 
Sabar, N. (2004). From heaven to reality through crisis: novice teachers as migrants. Teacher and Teacher Education, 20(2), 145-161.

Smith, T.M., \& Ingersoll, R.M. (2004). What are the effects of induction and mentoring on beginning teacher turnover? American Educational Research Journal, 41(3), 681-714.

The Statistical Yearbook of Abu Dhabi. (2009, 2010, 2011, 2012, 2013). National Statistics Centre, Abu Dhabi, UAE. Retrieved December 2013 from:

http://www.scad.ae/en/statistics/Pages/Statistics.aspx?ThemelD=7

Troudi, S. \& Alwan, F. (2010). Teachers' feelings during curriculum change in the United Arab Emirates: opening Pandora's box. Teacher Development, 14(1), 107-121.

UAE Ministry of Education. (2010). The Ministry of Education Strategy 2010 - 2020: 'Aiming in accomplishing a score of $10 / 10$ in all of its initiatives'.

Ünal, Z., \& Ünal, A. (2012). The impact of years of teaching experience on the classroom management approaches of elementary school teachers. International Journal of Instruction, 5(2), 41-60. 